\title{
Associations between tobacco use patterns and demographic characteristics of sexual minority and heterosexual youth: Results from a nationwide online survey
}

\author{
Joy L. Hart 1,2,3, S. Lee Ridner ${ }^{4}$, Lindsey A. Wood ${ }^{1,3}$, Kandi L. Walkerr, ${ }^{1,2,}$, Allison Groom ${ }^{2,5}$, Anshula Kesh ${ }^{2,5}$, Robyn L. Landry ${ }^{2,5}$, \\ Thomas J. Payne ${ }^{2,6}$, Jennie Z. Ma ${ }^{2,7}$, Rose Marie Robertson ${ }^{2,5}$, Paige E. Hart ${ }^{8}$, Aida L. Giachello2,9, Thanh-Huyen T. Vu ${ }^{2,9}$
}

\begin{abstract}
INTRODUCTION Youth are at risk for tobacco use, and previous research has pointed to increased vulnerabilities associated with sexual minority identity. For example, LGB youth have increased odds for using tobacco than their heterosexual peers, and bisexual youth have higher odds of smoking than other sexual identity groups. As new tobacco products proliferate and health risks from dual/poly use grow, increased understanding of tobacco use patterns by sexual minority youth is needed. METHODS For 3117 youth, aged 13-18 years, who completed an online questionnaire in 2017 and identified their sexual orientation [minority (e.g. lesbian/gay, bisexual, or pansexual) vs majority (heterosexual)] and gender, we classified current tobacco use into four categories: e-cigarette only, other product only ( such as cigarette, cigar, or smokeless tobacco; not an e-cigarette), dual/poly use, and no use. Analyses were conducted separately for male and female participants. Multinomial logistic regression was employed.

RESULTS Female sexual minority youth had nearly twofold odds of dual/ poly tobacco use ( $\mathrm{OR}=1.95$; 95\% CI: $1.12-3.40)$, compared to their heterosexual counterparts. For male youth, sexual minority identification was not significantly associated with dual/poly use. No significant differences were found in sexual minority and heterosexual youth e-cigarette only or other tobacco only use groups. Tobacco use patterns also significantly differed by age, race, place of residence, and parental education level.

CONCLUSIONS Study findings reveal greater odds of dual/poly tobacco use for female sexual minority youth. Tailored tobacco prevention and cessation programs or interventions are needed for sexual minority youth most at risk of tobacco use, especially multiple product use.
\end{abstract}

AFFILIATION

1 Department of Communication, University of Louisville, Louisville, United States

2 Tobacco Center for Regulatory Science,

American Heart Association, Dallas, United States

3 School of Medicine, University of Louisville,

Christina Lee Brown Envirome Institute,

Louisville, United States

4 College of Nursing, University of South

Alabama, Mobile, United States

5 American Heart Association, Dallas, United

States

6 Department of Otolaryngology and

Communicative Sciences, University of

Mississippi Medical Center, Jackson, United States

7 School of Medicine, Public Health Sciences,

University of Virginia, Charlottesville, United

States

8 School of Medicine, University of Louisville,

Louisville, United States

9 Department of Preventive Medicine, Feinberg

School of Medicine, Northwestern University,

Chicago, United States

\section{CORRESPONDENCE TO}

Thanh-Huyen T. Vu. Department of Preventive

Medicine, Feinberg School of Medicine,

Northwestern University, Chicago, IL, United

States. E-mail: huyenvu@northwestern.edu

\section{KEYWORDS}

youth, e-cigarette, sexual minority,

heterosexual, dual/poly tobacco use

Received: 28 May 2020

Revised: 14 October 2020

Accepted: 10 November 2020

\section{INTRODUCTION}

Health complications from tobacco use result in more preventable deaths in the US than any other cause ${ }^{1}$. Youth are especially at risk for tobacco use for several reasons. One reason is targeted marketing ${ }^{2-4}$, which persists despite regulations against targeting youth and denial of such targeting by tobacco companies. Another reason concerns physiological effects, such as the impact of nicotine on the developing brain ${ }^{1,5}$, and the risk of lifetime use after early exposure, given most 
initiate use before turning 18 years old. Further, some youth are more prone to increased tobacco use. For example, previous research has indicated that youth who identify as members of sexual minority groups are more likely to use tobacco ${ }^{6-9}$, including newer tobacco products such as e-cigarettes ${ }^{7,9}$. Furthermore, differences between male and female youth use have been identified. Male youth use cigarettes, cigars, smokeless tobacco, pipe tobacco, e-cigarettes and two or more products more often, relative to female youth ${ }^{10}$.

Although some research on tobacco has been conducted in youth sexual minority populations, significant additional work is needed to fully understand tobacco use drivers and patterns. For example, one investigation of middle and high school students in California, found that lesbian, gay, and bisexual (LGB) youth were more likely to smoke and vape than their heterosexual peers ${ }^{11}$. Another study, using US national data for high school students, reported that bisexual youth had higher odds of smoking compared to other sexual minority groups (i.e. lesbian or gay, and 'not sure' vs heterosexual) ${ }^{12}$. Study findings further indicated that, when assessed in subgroups by identity categories, bisexual male youth had increased odds of smoking $\geq 20$ of the past 30 days, compared to their heterosexual male peers ${ }^{12}$. Additionally, bisexual female youth had increased odds of vaping $\geq 10$ and $\geq 20$ of the past 30 days, and lesbians had higher odds of vaping $\geq 20$ of the past 30 days, compared to their heterosexual female peers ${ }^{12}$. Across the female groups, bisexuals had the greatest odds of smoking (overall, and for $\geq 10$ and $\geq 20$ days $)^{12}$.

Given the proliferation of new tobacco products (e.g. e-cigarettes) and increased health risks associated with dual/poly use, greater understanding of tobacco use by sexual minority youth is needed. This study's specific aim was to examine the associations of sexual minority status and demographic characteristics with tobacco use patterns. Gender differences in the associations were also investigated.

\section{METHODS}

\section{Sample}

For this American Heart Association Tobacco Center for Regulatory Science study, 3174 US youth, aged 13-18 years, completed an online questionnaire. Participants were recruited during August-October
2017 by a marketing research vendor experienced in youth recruitment. Using an online approach allowed recruitment of a diverse sample of US youth who were both e-cigarette users and never users. The research vendor maintains youth and young adult panels as well as recruits via buzz campaigns and social media. The Chesapeake/Advarra Institutional Review Board approved this study, and Children's Online Privacy Protection Act recommendations were followed. For participants aged $<18$ years, parental permission was secured; youth (<18 years) could elect whether or not to participate via an assent form. Consent (i.e. from participants aged 18 years and parents of youth aged 13-17 years) and assent (i.e. from youth aged 13-17 years whose parent consented) for study participation was obtained online via the vendor's research panel process. No identifying information was provided to the investigators. Data on age, gender identity, race, ethnicity, and geographical region were weighted to be representative of the overall US population. Due to 57 participants not reporting sexual orientation, 3117 participants were included in this analysis. Additional details on the survey have been published elsewhere ${ }^{13}$.

\section{Measures}

Participant characteristics included: age (13-14, 15-16, 17-18 years), gender identity (female or male, as no participants identified as transgender or other identities), sexual orientation (sexual minority [e.g. lesbian/gay, bisexual, or pansexual] vs majority or heterosexual [straight]), race (White, Black, other [Asian, Pacific Islander, Native American, bi/ multiracial]), ethnicity (Hispanic, non-Hispanic), socioeconomic status (SES: high vs low, with low indicating participant utilizing free/reduced-cost school lunch program or family receiving public assistance), and parental education level (less than associate's degree vs associate's degree or higher). Four current (i.e. past month) tobacco use groups were defined: e-cigarette only (uses only e-cigarettes, such as cigalikes, vape pens, mods, and vape pods), other tobacco product(s) only (uses one or more tobacco product(s), such as cigarettes, cigars, cigarillos, or smokeless tobacco, but does not use e-cigarettes), dual/poly (uses e-cigarettes and at least one other tobacco product), and no use (uses no tobacco products) (additional details in Supplementary file, Table S1 and Document 1). 


\section{Statistical analysis}

Descriptive statistics were conducted to compare characteristics of the study sample by sexual minority status. We used multinomial logistic regression models (odds ratios, ORs, with $95 \%$ confidence intervals, CIs) to examine the association between participants' sexual orientation and tobacco use patterns. An interaction term between gender and sexual minority status was employed, and it was significant. Therefore, analyses were stratified for male and female participants separately. Participants' age, race, ethnicity, family SES, place of residence, and parental education level were also included in the models. Two-sided statistical tests were considered significant for a p-value $\leq 0.05$. Statistical analyses were carried out with survey procedures using SAS statistical software (Version 9.4 with SAS/STAT 14.1, SAS Institute Inc., Gary, NC).

\section{RESULTS}

Characteristics of the analytic sample are shown in Table 1. Compared to the heterosexual group, the sexual minority group had similar characteristics but had a higher proportion of female youth $(75.7 \%$ vs $50.3 \%$ ) and youth from low-income households (59.9\% vs $47.2 \%)$. In examining associations, no significant differences in e-cigarette only or other tobacco only use between sexual minority and heterosexual youth were found (Table 1, Ref. = no use). Additionally, for male youth (sexual minority vs heterosexual), no significant differences were found in dual/poly use. For female youth, sexual minority youth had nearly twofold increased odds of dual/poly use $(\mathrm{OR}=1.95$; 95\% CI: 1.12-3.40), compared to their heterosexual peers. For both male and female youth, younger age was associated with lower odds of tobacco use for most categories of tobacco use. If a parent had attained an associate's or higher degree, male youth had decreased odds of e-cigarette only use ( $\mathrm{OR}=0.56$; $95 \% \mathrm{CI}$ : $0.34-$ $0.94)$ and increased odds of dual/poly use ( $\mathrm{OR}=1.66$; CI: 1.12-2.46) and female youth had approximately threefold odds of dual/poly use (OR $=3.16$; $95 \%$ CI: 1.70-5.87). Additionally, white female youth had more than twofold odds of other only use $(\mathrm{OR}=2.44$; 95\% CI: 1.01-5.85) than female youth of other race, non-Hispanic female youth had more than twofold the odds of dual/poly use (OR=2.71; $95 \%$ CI: $1.21-6.06)$ than Hispanic female youth, and urban/suburban male youth had 50-70\% fewer odds of other product(s) use than their rural counterparts.

Table 1. Multinomial logistic regression models for the associations between participant characteristics and current tobacco use patterns by gender identity ${ }^{a}$

\begin{tabular}{|c|c|c|c|c|c|c|}
\hline \multirow[t]{3}{*}{ Characteristics } & \multicolumn{3}{|c|}{ Male participants ( $n=1359)$} & \multicolumn{3}{|c|}{ Female participants $(n=1758)$} \\
\hline & $\begin{array}{c}E \text {-cig only } \\
(n=139)\end{array}$ & $\begin{array}{c}\text { Other onlyc } \\
(n=95)\end{array}$ & $\begin{array}{l}\text { Dual/polyd } \\
\qquad(n=270)\end{array}$ & $\begin{array}{c}\text { E-cig only } \\
(n=129)\end{array}$ & $\begin{array}{l}\text { Other only } \\
\qquad(n=160)\end{array}$ & $\begin{array}{c}\text { Dual/poly } \\
(n=138)\end{array}$ \\
\hline & OR $(95 \% \mathrm{CI})^{e}$ & OR $(95 \% \text { CI })^{e}$ & OR $(95 \% \text { CI })^{e}$ & OR $(95 \% \text { CI })^{e}$ & OR $(95 \% C I)^{e}$ & OR $(95 \% \text { CI })^{e}$ \\
\hline \multicolumn{7}{|l|}{$\begin{array}{l}\text { Sexual } \\
\text { orientation }\end{array}$} \\
\hline Sexual minority & $1.25(0.57-2.74)$ & $0.80(0.29-2.22)$ & $1.05(0.58-1.89)$ & $1.28(0.64-2.56)$ & $1.49(0.78-2.86)$ & $1.95(1.12-3.40)$ \\
\hline Heterosexual & Ref. & Ref. & Ref. & Ref. & Ref. & Ref. \\
\hline \multicolumn{7}{|l|}{ Age (years) } \\
\hline $13-14$ & $0.17(0.09-0.35)$ & $0.30(0.13-0.72)$ & $0.32(0.19-0.52)$ & $0.52(0.20-1.40)$ & $0.36(0.13-0.99)$ & $0.01(0.00-0.09)$ \\
\hline $15-16$ & $0.77(0.46-1.29)$ & $0.51(0.27-0.97)$ & $0.82(0.54-1.23)$ & $0.51(0.27-0.98)$ & $0.16(0.06-0.39)$ & $0.24(0.12-0.50)$ \\
\hline $17-18$ & Ref. & Ref. & Ref. & Ref. & Ref. & Ref. \\
\hline \multicolumn{7}{|l|}{ Race } \\
\hline White & $2.00(0.93-4.33)$ & $1.37(0.44-4.27)$ & $1.13(0.64-1.97)$ & $1.78(0.79-4.02)$ & $2.44(1.01-5.85)$ & $1.20(0.58-2.49)$ \\
\hline Black & $0.78(0.29-2.10)$ & $0.92(0.27-3.23)$ & $0.64(0.31-1.30)$ & $0.58(0.11-1.83)$ & $0.47(0.17-1.30)$ & $2.15(0.78-5.94)$ \\
\hline Other ${ }^{f}$ & Ref. & Ref. & Ref. & Ref. & Ref. & Ref. \\
\hline \multicolumn{7}{|l|}{ Ethnicity } \\
\hline Non-Hispanic & $1.16(0.58-2.32)$ & $0.77(0.35-1.68)$ & $1.20(0.72-2.01)$ & $1.21(0.44-3.33)$ & $1.74(0.81-3.76)$ & $2.71(1.21-6.06)$ \\
\hline Hispanic & Ref. & Ref. & Ref. & Ref. & Ref. & Ref. \\
\hline
\end{tabular}


Table 1. Continued

\begin{tabular}{|c|c|c|c|c|c|c|}
\hline \multirow[t]{3}{*}{ Characteristics } & \multicolumn{3}{|c|}{ Male participants ( $n=1359)$} & \multicolumn{3}{|c|}{ Female participants ( $n=1758)$} \\
\hline & $\begin{array}{c}E^{-c i g} \text { only } \\
(n=139)\end{array}$ & $\begin{array}{c}\text { Other only } \\
\qquad(n=95)\end{array}$ & $\begin{array}{l}\text { Dual/polyd } \\
(n=270)\end{array}$ & $\begin{array}{l}\text { E-cig only } \\
(n=129)\end{array}$ & $\begin{array}{l}\text { Other only } \\
(n=160)\end{array}$ & $\begin{array}{c}\text { Dual/poly } \\
(n=138)\end{array}$ \\
\hline & OR $(95 \% \mathrm{CI})^{\mathrm{e}}$ & OR $(95 \% \text { CI })^{e}$ & OR $(95 \% \mathrm{CI})^{e}$ & OR $(95 \% \mathrm{CI})^{\mathrm{e}}$ & OR $(95 \% \mathrm{CI})^{e}$ & OR $(95 \% \text { CI })^{e}$ \\
\hline \multicolumn{7}{|l|}{$\begin{array}{l}\text { Family } \\
\text { socioeconomic } \\
\text { status }\end{array}$} \\
\hline High income & $1.02(0.60-1.71)$ & $0.73(0.37-1.43)$ & $0.70(0.47-1.04)$ & $0.86(0.43-1.71)$ & $0.49(0.22-1.10)$ & $0.62(0.34-1.13)$ \\
\hline Low income ${ }^{g}$ & Ref. & Ref. & Ref. & Ref. & Ref. & Ref. \\
\hline \multicolumn{7}{|l|}{$\begin{array}{l}\text { Parental } \\
\text { education level }\end{array}$} \\
\hline $\begin{array}{l}\text { Less than } \\
\text { associate's degree }\end{array}$ & $0.56(0.34-0.94)$ & $1.50(0.76-2.98)$ & $1.66(1.12-2.46)$ & $0.59(0.31-1.12)$ & $1.34(0.63-2.89)$ & $3.16(1.70-5.87)$ \\
\hline $\begin{array}{l}\text { Associate's degree } \\
\text { or higher }\end{array}$ & Ref. & Ref. & Ref. & Ref. & Ref. & Ref. \\
\hline \multicolumn{7}{|l|}{$\begin{array}{l}\text { Place of } \\
\text { residence }\end{array}$} \\
\hline Urban & $1.11(0.58-2.14)$ & $0.49(0.24-1.00)$ & $1.28(0.75-2.19)$ & $1.02(0.44-2.38)$ & $1.04(0.49-2.20)$ & $1.30(0.59-2.87)$ \\
\hline Suburban & $0.84(0.43-1.66)$ & $0.31(0.15-0.63)$ & $1.05(0.62-1.78)$ & $1.32(0.61-2.84)$ & $0.56(0.22-1.38)$ & $1.87(0.90-3.90)$ \\
\hline Rural & Ref. & Ref. & Ref. & Ref. & Ref. & Ref. \\
\hline
\end{tabular}

Ref.: reference group for tobacco use patterns (outcome) - no use (used no tobacco products). a Gender identity: participants were asked to identify their gender including male, female, transgender and other (specify). However, no participant identified as a gender minority. b E-cig only: use only e-cigarette products such as cigalike, vape pen, mod, vape pod, e-cigar, e-pipe, e-hookah or list any other types of e-cigarettes. c Other only: use only a non-e-cigarette product(s) such as traditional cigarettes, cigars, cigarillos, bidis, hookahs, dissolvables, smokeless tobacco, or list any other type of non-e-cigarette products. d Dual/poly: use e-cigarette and at least one other tobacco product. e Odds ratios (OR) and 95\% confidence intervals $(\mathrm{Cl})$ in multivariable logistic regression models. Proc Surveylogistic was used to account for sampling probability. $\mathrm{f}$ Other race included Asian/Pacific Islander, American Indian/Alaska Native, and bi/multiracial. g Low income: participated in a free/reduced cost lunch program at school or family receiving public assistance (e.g. Medicaid, Section 8 housing, Obama phone, food stamps).

\section{DISCUSSION}

Sexual minority identification was not significantly associated with an increased likelihood of dual/poly tobacco use for participants who identified as male; however, for participants who identified as female, a twofold increase was observed. Previous studies have found higher tobacco use rates in youth who identify as bisexual ${ }^{8,14}$, including increased risk in adolescent bisexual girls ${ }^{7,12,14}$ and lesbians ${ }^{7,12}$, pointing to increased risk for usage and ultimately adverse health outcomes for sexual minority girls ${ }^{15}$. Although studies with youth sexual minority subpopulations are few, research with adults has reported that lesbians and bisexual women have greater odds of tobacco $\mathrm{use}^{16}$, including dual use $\mathrm{e}^{17}$, with some research suggesting that bisexual women are particularly at risk $^{18,19}$. However, this study is one of the first to report significantly greater odds of dual/poly tobacco use by female sexual minority youth. Given that dual/ poly use often involves the consumption of newer tobacco products where the health risks are yet to be understood, especially when combined across multiple products, this finding elevates public health concerns for this priority population.

Interestingly, having a parent who completed an associate's or higher degree may provide a protective effect for boys' e-cigarette only use but not for girls' or boys' dual/poly use; in fact, girls with a parent who completed an associate's or higher degree had significantly greater odds of dual/poly tobacco use. Additional research is needed to understand the mechanisms underlying this differential effect.

\section{Strengths and limitations}

Several limitations affect the interpretation of this study's results. First, the cross-sectional nature of the research means that temporality cannot be assessed. Second, self-reported information is subject to potential biases (e.g. recall, response). Third, there is also the possibility of sampling bias. For example, 
internet access was required to participate; thus, individuals with limited internet access may not have participated. Also, youth who were not interested in the research topic may have elected not to participate. Despite these limitations, the study's strengths include a nationwide sample of youth, the focus on potential differences by sexual orientation and gender, and examining e-cigarette and dual/poly use, which are tobacco use categories with increasing public health relevance.

\section{CONCLUSIONS}

In this nationwide online survey of more than 3000 participants, the odds of dual/poly tobacco use were higher for female youth who identified as sexual minorities. Additional research with sexual minority youth subpopulations is needed to better understand factors mediating differential tobacco use patterns. Also, health communication programs or interventions targeted to sexual minority youth regarding the dangers of tobacco consumption, especially use of multiple products, are needed.

\section{REFERENCES}

1. U.S. Department of Health and Human Services. The Health Consequences of Smoking-50 Years of Progress. A Report of the Surgeon General. Atlanta, GA: Centers for Disease Control and Prevention (US); 2014. https://www. cdc.gov/tobacco/data_statistics/sgr/50th-anniversary/ index.htm. Accessed April 24, 2020.

2. Mantey DS, Cooper MR, Clendennen SL, Pasch KE, Perry CL. E-cigarette marketing exposure is associated with e-cigarette use among US youth. J Adolesc Health. 2016;58(6):686-690. doi:10.1016/j.jadohealth.2016.03.003

3. Soneji S, Yang J, Knutzen KE, Moran MB, Tan ASL, Sargent J, Choi K. Online tobacco marketing and subsequent tobacco use. Pediatrics. 2018;141(2):e20172927. doi:10.1542/peds.2017-2927

4. U.S. Department of Health and Human Services. Preventing Tobacco Use Among Youth and Young Adults: A Report of the Surgeon General. Atlanta, GA: Centers for Disease Control and Prevention (US); 2012. https:// www.ncbi.nlm.nih.gov/books/NBK99237/. Accessed March 15, 2020.

5. Goriounova NA, Mansvelder HD. Short- and long-term consequences of nicotine exposure during adolescence for prefrontal cortex neuronal network function. Cold Spring Harb Perspect Med. 2012;2(12):a012120. doi:10.1101/cshperspect.a012120

6. Johnston LD, Miech RA, O'Malley PM, Bachman JG, Schulenberg JE, Patrick ME. Monitoring the Future national survey results on drug use 1975-2018: Overview, key findings on adolescent drug use. https://files.eric. ed.gov/fulltext/ED594190.pdf. Published 2019. Accessed April 16, 2020.

7. Dai H. Tobacco product use among lesbian, gay, and bisexual adolescents. Pediatrics. 2017;139(4):e20163276. doi:10.1542/peds.2016-3276

8. Azagba S, Asbridge M, Langille D, Baskerville B. Disparities in tobacco use by sexual orientation among high school students. Prev Med. 2014;69:307-311. doi:10.1016/j.ypmed.2014.07.042

9. Kann L, Olsen EO, McManus T, et al. Sexual identity, sex of sexual contacts, and health-related behaviors among students in grades 9-12-United States and selected sites, 2015. MMWR Surveill Summ. 2016;65(9):1-202. doi:10.15585/mmwr.ss6509a1

10. Gentzke AS, Creamer M, Cullen KA, et al. Vital signs: Tobacco product use among middle and high school students-United States, 2011-2018. MMWR Morb Mortal Wkly Rep. 2019;68(6):157-164. doi:10.15585/mmwr.mm6806e1

11. Coulter RWS, Bersamin M, Russell ST, Mair C. The effects of gender- and sexuality-based harassment on lesbian, gay, bisexual, and transgender substance use disparities. J Adolesc Health. 2018;62(2):688-700. doi:10.1016/j.jadohealth.2017.10.004

12. Azagba S, Latham K, Shan L. Cigarette smoking, e-cigarette use, and sexual identity among high school students in the USA. Eur J Pediatr. 2019;178(9):13431351. doi:10.1007/s00431-019-03420-w

13. Pfeiffer JA, Tompkins LK, Hart JL, et al. Relationship between population characteristics, e-cigarette and tobacco-related perceptions, and likelihood of ever using e-cigarettes. Tob Prev Cessation. 2020;6(March):1-12. doi:10.18332/tpc/117477

14. Corliss HL, Rosario M, Birkett MA, Newcomb ME, Buchting FO, Matthews AK. Sexual orientation disparities in adolescent cigarette smoking: Intersections with race/ethnicity, gender, and age. Am J Public Health. 2014;104(6):1137-1147. doi:10.2105/AJPH.2013.301819

15. Johnson SE, O'Brien EK, Coleman B, Tessman GK, Hoffman L, Delahanty J. Sexual and gender minority U.S. youth tobacco use: Population Assessment of Tobacco and Health (PATH) Study Wave 3, 2015-2016. Am J Prev Med. 2019;57(2):256-261. doi:10.1016/j.amepre.2019.03.021

16. Emory K, Kim Y, Buchting F, Vera L, Huang J, Emery SL. Intragroup variance in lesbian, gay, and bisexual tobacco use behaviors: Evidence that subgroups matter, notably bisexual women. Nicotine Tob Res. 2016;18(6):14941501. doi:10.1093/ntr/ntv20

17. Ridner SL, Ma JZ, Walker KL, et al. Cigarette smoking, ENDS use and dual use among a national sample of lesbians, gays and bisexuals. Tob Prev Cessat. 2019;5(December):1-6. doi:10.18332/tpc/114229

18. Hoffman L, Delahanty J, Johnson SE, Zhao X. Sexual 
and gender minority cigarette smoking disparities: An analysis of 2016 Behavioral Risk Factor Surveillance System data. Prev Med. 2018;113:109-115. doi:10.1016/j.ypmed.2018.05.014

19. Johnson SE, Holder-Hayes E, Tessman GK, King BA, Alexander T, Zhao X. Tobacco product use among sexual minority adults: Findings from the 2012-2013 National Adult Tobacco Survey. Am J Prev Med. 2016;50(4):e91-e100. doi:10.1016/j.amepre.2015.07.041

CONFLICTS OF INTEREST

The authors have each completed and submitted an ICMJE form for disclosure of potential conflicts of interest. The authors declare that they have no competing interests, financial or otherwise, related to the current work. J. L. Hart, A. L. Giachello, A. Groom, A. Kesh, R. Landry, J. Ma, T. Payne, R. M. Robertson, T. H. Vu, K. Walker and L. Wood report grants from National Institutes of Health, during the conduct of the study.

\section{FUNDING}

This work was supported by the National Heart, Lung, and Blood Institute (NHLBI) of the National Institutes of Health (NIH) and FDA Center for Tobacco Products under Award Numbers P50HL120163 and U54HL120163. The content is solely the responsibility of the authors and does not necessarily represent the official views of the $\mathrm{NIH}$, the Food and Drug Administration, or the American Heart Association. The funding sponsors had no role in study design; data collection, analyses, or interpretation; manuscript preparation; or the decision to publish the results.

PROVENANCE AND PEER REVIEW

Not commissioned; externally peer reviewed. 